\title{
Multi-fault system of the 2004 Mid-Niigata Prefecture Earthquake and its aftershocks
}

\author{
Shin'ichi Sakai, Naoshi Hirata, Aitaro Kato, Eiji Kurashimo, Takaya Iwasaki, and Toshihiko Kanazawa \\ Earthquake Research Institute, University of Tokyo, 1-1-1 Yayoi, Bunkyo-ku, Tokyo 113-0032, Japan
}

(Received February 16, 2005; Revised April 18, 2005, 2005; Accepted April 20, 2005)

\begin{abstract}
A seismic network was deployed the day after the main shock of the 2004 Mid-Niigata Prefecture Earthquake to determine the major source faults responsible for the main shock and large aftershocks. Using the high-resolution seismic data for five days, three major source faults were identified: two parallel faults dipping steeply to the west located $5 \mathrm{~km}$ apart, and another dipping eastward and oriented perpendicular to the west-dipping faults. Strong lateral changes in the velocity of the source area resulted in the locations of the epicenters determined in this study being located approximately $4.3 \mathrm{~km}$ west-north-west of those reported by the JMA routine catalogue. The strong heterogeneity of the crust is related to the complex geological and tectonic evolution of the area and therefore the relatively large aftershocks followed around the main shock. This is considered to be responsible for the prominent aftershock activity following the 2004 Niigata event.
\end{abstract}

Key words: 2004 Mid-Niigata Prefecture earthquake, urgent aftershock observation, precise aftershock distribution, multi-fault system.

\section{Introduction}

The 2004 Mid-Niigata Prefecture Earthquake $\left(\mathrm{M}_{J M A}\right.$ 6.8) occurred in central Japan at 17:56 on October 23, 2004 (JST). The event caused the destruction of as many as 10 000 dwellings, 46 fatalities and left 4000 people injured (Fig. 1). The earthquake was initially reported by the Japan Meteorology Agency (JMA) at a relatively shallow depth of $13 \mathrm{~km}$ in an active fault-and-fold system overlaid by thick sediments. Although this earthquake generated many fissures and landslides, there was no clear evidence that known active faults were responsible for the present earthquake. Also, the western Nagaoka plane active fault, one of the 98 major active faults reported by the Japanese Government (Headquarters for Earthquake Research Promotion, 1999) did not exhibit any activity during this event despite lying only $10 \mathrm{~km}$ to the west of the epicenter. A JMA earthquake intensity of 7 was recorded in Kawaguchi and Ojiya and the event was followed by highly prominent aftershock activity, with five major aftershocks of M 5.5 or greater on October 23, and others on October 25 (M 5.8), October 27 (M 6.1) and November 8 (M 5.9), more than twice as many as occurred in the disastrous 1995 Hyogo-ken Nanbu (Kobe) earthquake (Hirata et al., 1996).

Japan has one of the densest arrays of seismic stations in the world (Obara, 2000). Nonetheless, the average distance of approximately $20 \mathrm{~km}$ between permanent telemetry stations is insufficient to precisely locate events shallower than $15 \mathrm{~km}$. Furthermore, in areas such as the Mid-Niigata Prefecture Earthquake where the lateral variation of velocity is severe, routine determination of the hypocenter us-

Copy right(c) The Society of Geomagnetism and Earth, Planetary and Space Sciences (SGEPSS); The Seismological Society of Japan; The Volcanological Society of Japan; The Geodetic Society of Japan; The Japanese Society for Planetary Sciences; TERRAPUB. ing a one-dimensional velocity model with data from the permanent stations may introduce a systematic bias with respect to both epicenter location and depth. Although the focal mechanisms of the main shock indicated that the east-west compression of the regional stress field formed a thrust fault, the reported aftershock distribution was not clear enough to identify which nodal plane wais responsible for the main shock faulting.

Immediately following the main shock, we deployed a temporary seismic array in the epicenter region to capture detailed aftershock data for analysis of the faulting mechanism. The data from the temporary high-resolution network the day after the main shock were expected to reveal the source area of the main shock and its migration in the aftershock succession. Although we finally installed fifty-six seismographs in the source area for approximately one month, data form fourteen seismographs which were recorded in early period were used for analysis in this study. The data were collected over the five days period following the main shock to better understand the principle components of the aftershock activity that immediately followed the Mid-Niigata Prefecture earthquake. An analysis of the entire one-month data set with special attention devoted to the spatiotemporal variation in the cluster activity of the aftershock is presented elsewhere (Kato et al., 2005b, this issue).

\section{Urgent Seismic Observation}

Although the source area is covered by the permanent seismic network, the average interval is approximately 20 $\mathrm{km}$ between telemetry stations, combined with disruptions in electricity supply to the stations close to the source area after the main shock, meant that data for the area was insufficient at the time of the main shock. Given that the 


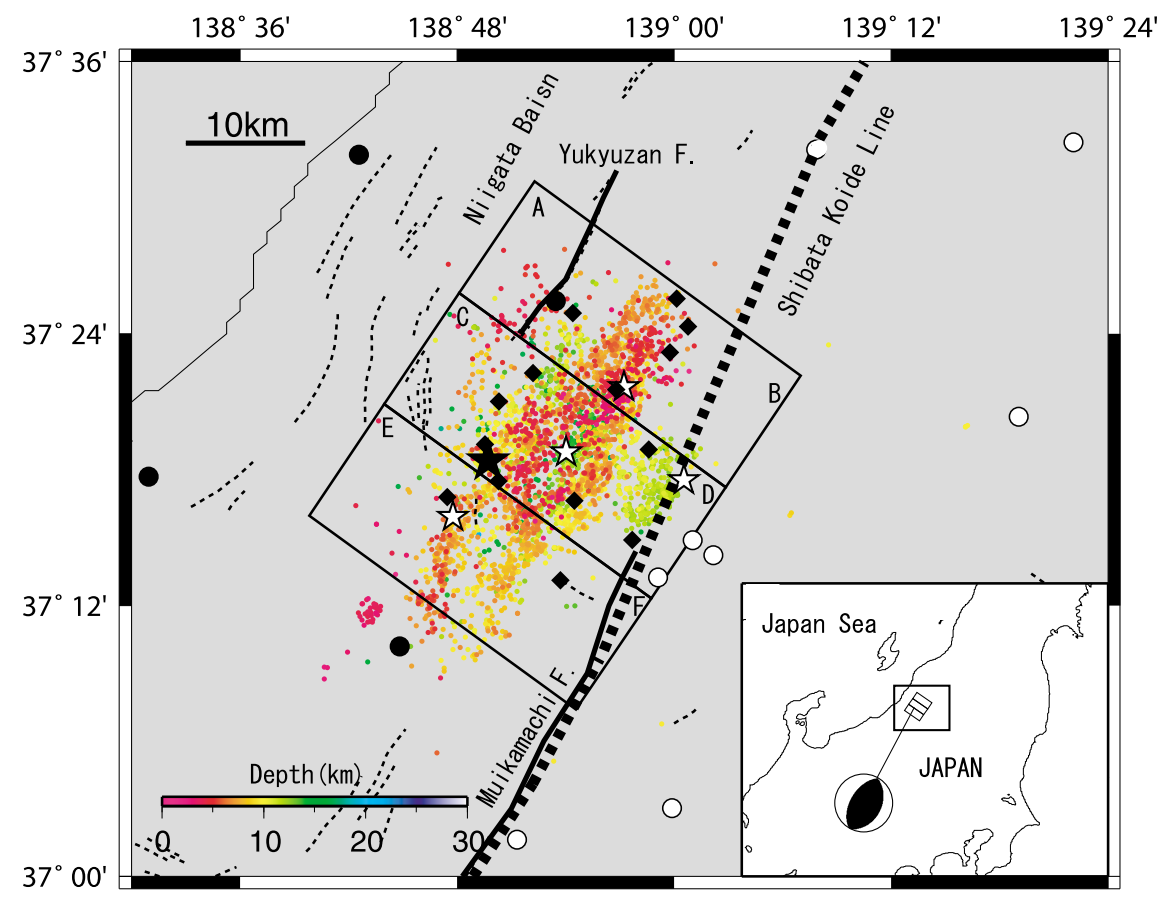

Fig. 1. Location map of the 2004 Mid-Niigata Prefecture earthquake. The study area is indicated by a solid square (inset map). A focal mechanism solution for the main shock is shown using lower hemisphere projection. Focal depth of the earthquakes is indicated using a color scale, blue corresponds to deep and red corresponds to shallow. Stars indicate the main shock and the large aftershock. Solid lines indicate the Yukyuzan fault and the Muikamachi fault. The broken line indicates the Shibata-Koide Line. Diamonds and circles indicate the location of 14 temporary stations that were recovered on October 28, and the permanent stations, respectively. The observation stations indicated by open circles were using the eastern structure in Fig. 2. Solid diamonds and solid circles were indicated the observation station using the western structure. The regions of the cross-sections in Fig. 4 are indicated by boxes.

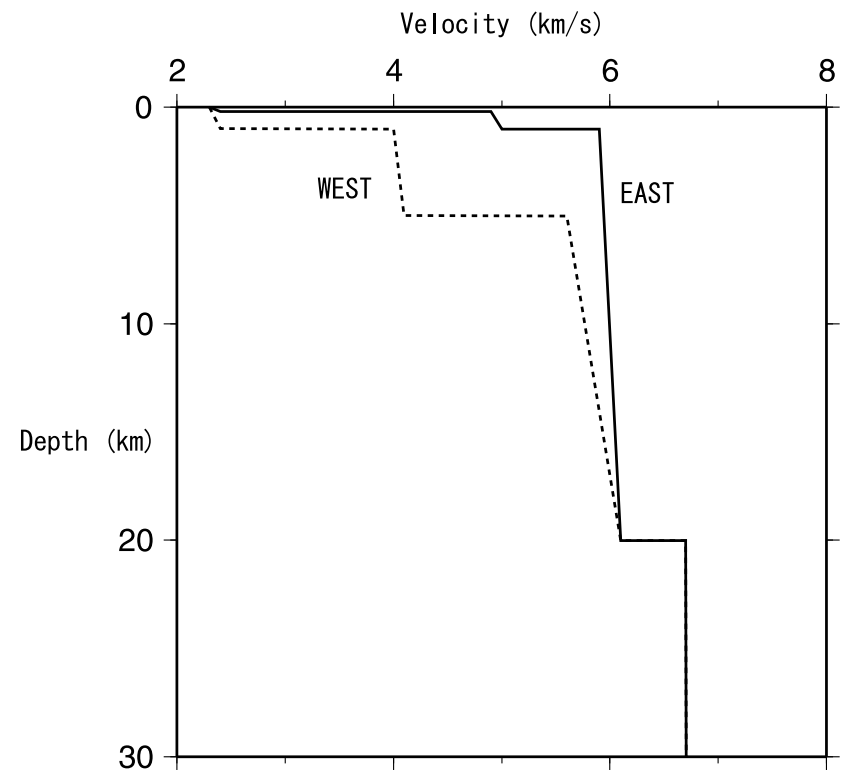

Fig. 2. $P$-wave velocity structure models used for hypocenter determination. The model is derived from the refraction study (Takeda et al., 2004). Solid and broken lines indicate the models for the stations on the east and west of the SKL, respectively.

routine surveillance conducted by the JMA is not sufficient for clarifying the distribution of the aftershocks, in detail, we deployed seismographs the day after the main shock in the source region (Fig. 1, Table 1). We installed fiftysix battery-powered seismometers by November 8, 2004, which we then operated for one month. The use of battery8 powered seismographs is essential in the areas where electric power supply has been disrupted. Some of the stations were also equipped with a very small seismograph, connected to a $200 \mathrm{~mm} \times 120 \mathrm{~mm} \times 75 \mathrm{~mm}$ data logger which had been developed for a controlled source experiment. All of the deployed seismographs continuously recorded a 3component geophone signal at a sampling rate of 100 or $200 \mathrm{~Hz}$. All of the recorders were equipped with a GPS receiver to maintain internal clock accuracy in the order of $1 \mathrm{~ms}$.

To understand the aftershock activity immediately following the main shock, and to assess whether any migration of activity occurred, we retrieved the fourteen seismographs five days after the main shock on October 28. These data include the large M6.1 aftershock on October 27.

\section{Hypocenter Determination}

We process the continuously recorded field data according to the procedure set out in the JMA catalogue for the integrated processing of data from the JMA, the Hi-net, and the universities. $P$ - and $S$-wave arrival times were manually picked on a computer display (Urabe and Tsukada, 1991). Given the strong lateral heterogeneity that exists across the Shibata-Koide Line (SKL), west of which is the Niigata basin with a thick sedimentary layer (Natural Gas Mining Society and the Society of Exploration for Oil in the Continental shelf, 1992), we used two one-dimensional velocity models (Fig. 2)-for estimating the location of hypocenter based on a previous refraction study (Takeda $e t$ 
Table 1. Summary of the positions, station-corrections, operation period and adopted structures of the temporary stations.

\begin{tabular}{cccrrrrr}
\hline Station & Latitude (degree) & Longitude (degree) & Elevation $(\mathrm{m})$ & \multicolumn{2}{c}{ Station-correction } & Operation & Structure \\
& & & & \multicolumn{1}{c}{$P(\mathrm{~s})$} & \multicolumn{1}{c}{$S(\mathrm{~s})$} & & \\
\hline ST03.L8 & 37.31860 & 138.82570 & 50 & -0.40 & -0.58 & Oct. 25-28 & WEST \\
ST05B.L8 & 37.27980 & 138.79110 & 100 & -0.62 & -1.15 & Oct. 25-28 & WEST \\
ST05.L8 & 37.29140 & 138.83830 & 125 & -0.33 & -0.47 & Oct. 25-28 & WEST \\
ST16.L8 & 37.41500 & 138.90650 & 115 & -0.12 & 0.18 & Oct. 25-28 & WEST \\
ST18.L8 & 37.40540 & 139.01290 & 355 & 0.14 & 0.46 & Oct. 24-27 & WEST \\
ST19B.L8 & 37.35010 & 138.83870 & 65 & -0.24 & -0.22 & Oct. 25-28 & WEST \\
ST19.L8 & 37.37110 & 138.86990 & 95 & -0.09 & 0.11 & Oct. 25-28 & WEST \\
ST20.L8 & 37.38610 & 138.99610 & 285 & 0.11 & 0.38 & Oct. 24-28 & WEST \\
ST25.L8 & 37.42610 & 139.00170 & 260 & 0.08 & 0.27 & Oct. 24-27 & WEST \\
ST02.D1 & 37.35881 & 138.94688 & 337 & 0.22 & 0.70 & Oct. 24-27 & WEST \\
ST06.D1 & 37.27650 & 138.90800 & 100 & -0.15 & -0.13 & Oct. 24-28 & WEST \\
ST07.D & 37.31485 & 138.97667 & 300 & 0.30 & 0.92 & Oct. 24-27 & WEST \\
ST13.D & 37.21830 & 138.89505 & 133 & -0.25 & -0.32 & Oct. 25-28 & WEST \\
ST24.D & 37.24808 & 138.96146 & 131 & 0.15 & 0.58 & Oct. 25-28 & WEST \\
\hline
\end{tabular}

Table 2. Summary of the station-corrections and adopted structures of the permanent stations.

\begin{tabular}{|c|c|c|c|c|c|c|c|}
\hline \multirow[t]{2}{*}{ Station } & \multicolumn{2}{|c|}{ Station-correction } & \multirow[t]{2}{*}{ Structure } & \multirow[t]{2}{*}{ Station } & \multicolumn{2}{|c|}{ Station-correction } & \multirow[t]{2}{*}{ Structure } \\
\hline & $P(\mathrm{~s})$ & $S(\mathrm{~s})$ & & & $P(\mathrm{~s})$ & $S(\mathrm{~s})$ & \\
\hline HRG & -0.37 & -0.17 & EAST & TDMH & -0.44 & 0.01 & EAST \\
\hline SEK & -0.13 & 0.74 & EAST & MUIH & -0.36 & -0.06 & EAST \\
\hline KZK & -0.30 & -0.01 & WEST & SZWH & -0.69 & -0.66 & EAST \\
\hline YHJ & 0.11 & 0.74 & WEST & MNKH & -0.07 & 0.58 & EAST \\
\hline TNN & 0.09 & 0.60 & WEST & YZWH & -0.03 & 0.64 & EAST \\
\hline KNY & -0.26 & 0.53 & EAST & MAKH & -0.39 & -0.28 & WEST \\
\hline HIROKA & -0.39 & -0.26 & EAST & INAH & -0.30 & 0.53 & EAST \\
\hline IZUMOZ & -0.85 & -1.41 & WEST & КМКН & -0.46 & 0.00 & EAST \\
\hline NAKAMA & -0.02 & 0.12 & WEST & TWAH & -0.70 & -0.40 & EAST \\
\hline SASAKA & 0.96 & 2.34 & WEST & KYWH & 0.08 & 1.14 & EAST \\
\hline YNTH & -0.52 & -0.40 & EAST & $\mathrm{KMOH}$ & -0.37 & -0.39 & WEST \\
\hline KWNH & -0.69 & -0.98 & WEST & MRMH & 0.87 & 2.22 & WEST \\
\hline $\mathrm{NGOH}$ & -0.12 & 0.10 & WEST & $\mathrm{MKOH}$ & -0.44 & -0.67 & WEST \\
\hline STDH & -0.77 & -0.72 & EAST & NZWH & 0.42 & 1.17 & WEST \\
\hline
\end{tabular}

Table 3. Comparison hypocenters of the main shock and the large aftershocks.

\begin{tabular}{cccc}
\hline Date (JST) & Latitude (degree) & Longitude (degree) & Depth $(\mathrm{km})$ \\
\hline 20041023175559.42 & 37.30643 & 138.82843 & 12.60 \\
2004102318311.96 & 37.36079 & 138.95397 & 9.31 \\
20041023181156.38 & 37.26534 & 138.79614 & 12.17 \\
2004102318344.80 & 37.31305 & 138.90067 & 15.78 \\
20041027104049.49 & 37.29227 & 139.00924 & 13.59 \\
\hline
\end{tabular}

al., 2004). Two one-dimensional velocity structures were used for the calculation of travel times of the stations depending on whether the station was located to the east or west of the SKL. Given that the thickness of the sedimentary layers differs from one observational station to another, station-corrections were estimated and applied to the calculation of hypocenter location as follows.

First, we estimated the location of aftershocks using a maximum-likelihood estimation algorithm (Hirata and
Matsu'ura, 1987) and obtained residuals for the arrival times of $P$ - and $S$-waves. We assumed that the ratio of $P$-wave velocity $(V p)$ to $S$-wave velocity $(V s)$ in the sedimentary layer was 3.0 and that it was 1.73 in the other layers (Natural Gas Mining Society and the Society of Exploration for Oil in the Continental shelf, 1992). The average of the residuals was used as an initial value for the estimated station-correction for the calculated arrival time at each station. Next, we relocated the hypocenter to fourteen tempo- 
(a)
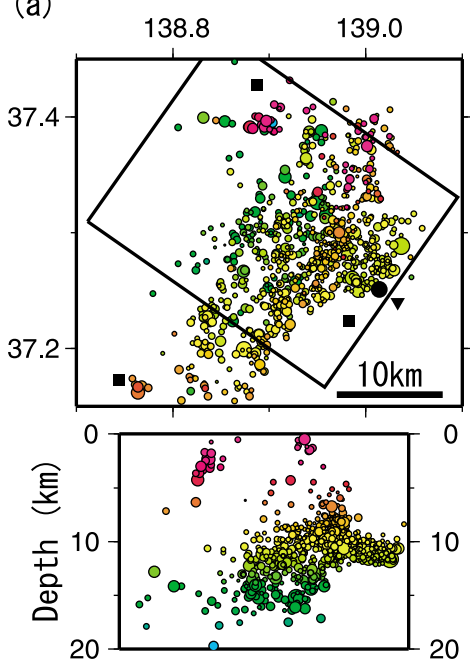

(b)

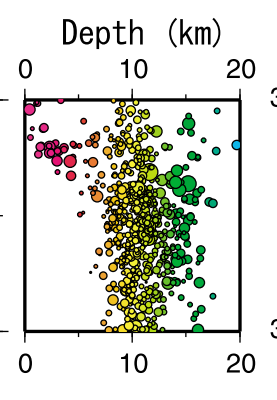

JMA

M2 M3 M4
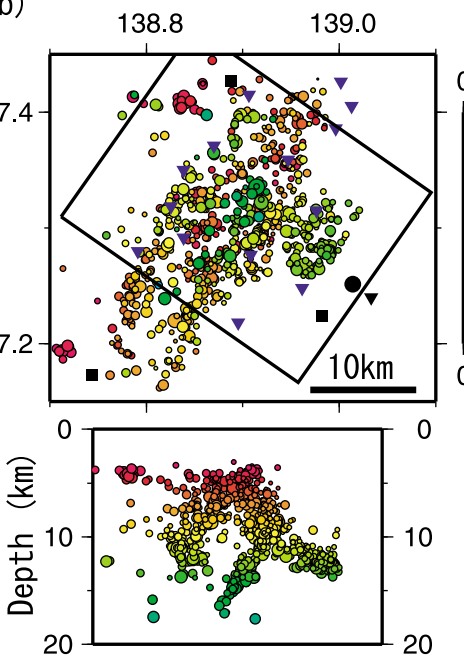

Depth (km)

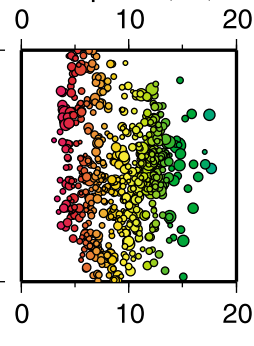

This study

M2 M3 M4

Fig. 3. Comparison between the hypocenters determined by JMA (a) and those determined in this study (b). The focal depth of the earthquakes is indicated by a color scale; blue corresponds to deep and red corresponds to shallow. Vertical sections along the rectangular in the epicentral maps are also shown; this rectangular is converted to the strike of the geological structure in the region. The epicenters determined by this temporary observation are located approximate $4 \mathrm{~km}$ west of those reported by the JMA routine catalogue. Most of hypocenters determined by the JMA were deeper than $10 \mathrm{~km}$ while some reported in this study had focal depths shallower than $10 \mathrm{~km}$.
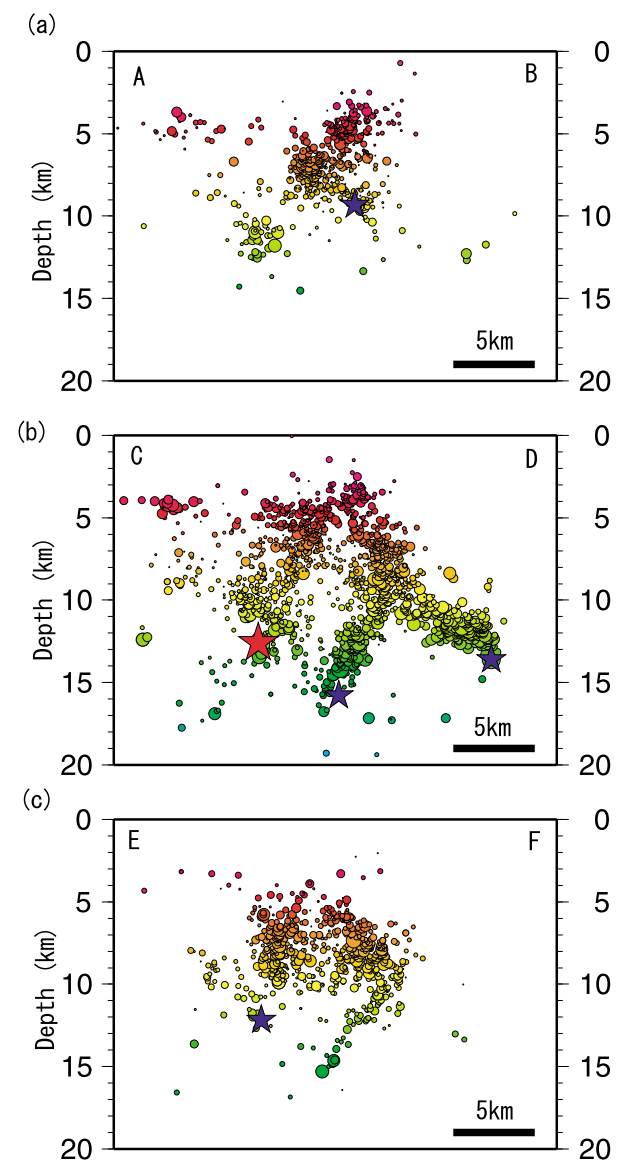

Fig. 4. Cross-section of reliable aftershocks. The strike of the cross section is $55^{\circ}$ from north to west and perpendicular to the direction of the geological structure in this region. Depth distributions are shown in three regions; (a) northeastern, (b) central (c) southwestern regions (shown by rectangular in Fig. 1). Red and blue stars indicate the main shock and large aftershocks, respectively. rary stations and five permanent telemetered stations near the main shock to calculate the travel time residuals for the relocated hypocenters. We relocated them once more using new station-corrections calculated previously by the residuals. This procedure was repeated five times to obtain average residuals of less than $0.01 \mathrm{~s}$. Finally, we obtained relocated aftershocks and station-corrections for the fourteen temporary and the five permanent stations near the source area.

Next, we added picked arrival time data at one permanent station, which is the nearest to the main shock, to the abovementioned data set. The hypocenters were relocated once more to account for the station-correction of the added station. The next nearest station was then added to the data set until we had station-corrections for twenty-eight permanent stations (Table 2). These were used to relocate events that occurred before our temporary observation data was collected, including the main shock and the largest aftershock. The station corrections resulted in the root-mean-squares (rms) of the residuals decreased from $0.175 \mathrm{~s}$ to $0.074 \mathrm{~s}$ for $P$-wave arrival and those for $S$-wave arrival from $0.476 \mathrm{~s}$ to $0.166 \mathrm{~s}$ owing to the station-corrections.

The master event method was used to relocated the main shock and the large aftershocks (Douglas, 1967). Master events were selected from among those aftershocks, determined by this temporary observation data, as those which had distribution of arrival time residuals closest to those of the main shock and the large aftershocks. The relocated hypocenters are listed in Table 3.

\section{Discussion}

We relocated 862 events listed in the JMA catalogue and selected 739 hypocenters with spatial errors of less than $0.5 \mathrm{~km}$ in the horizontal direction and less than $1 \mathrm{~km}$ deep. The hypocenters determined by the temporary stations deployed in this study were located approximately $4.3 \mathrm{~km}$ 


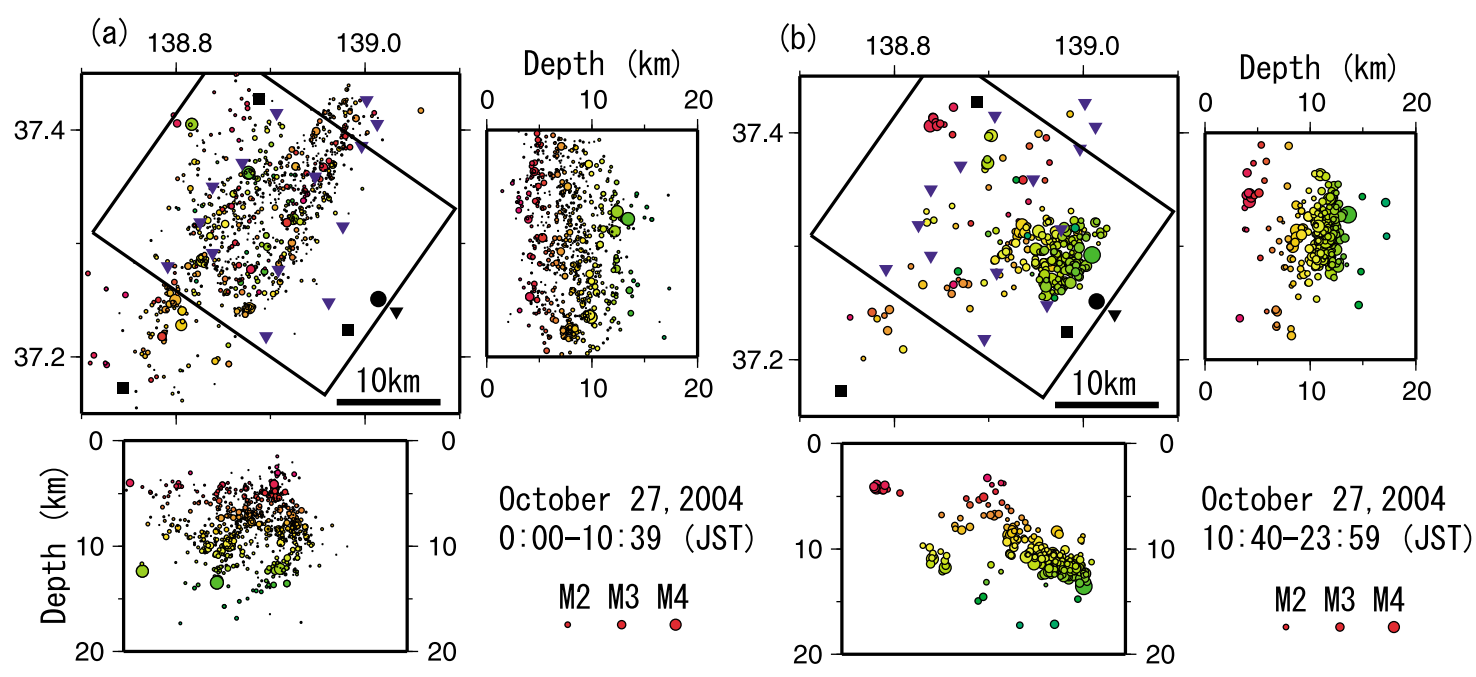

Fig. 5. Comparison of aftershock distributions before and after the Oct. 27 10:40 aftershock (M6.1). Aftershock distribution for the ten hours before the M6.1 event (a) and that after the event (b) are shown. The focal depth of the earthquakes is color-coded; blue corresponds to deep and red corresponds to shallow. Vertical sections along the rectangular in the epicentral maps are also shown.

west-northwest from the location given by the JMA (Fig. 3). The distinct lateral heterogeneity of the velocity structure could account for these differences. The western part of the source region is located in the Niigata basin and is characterized as having a thick sedimentary layer with a marked contrast in the seismic velocity exists between the eastern and western regions. Our estimated station-corrections clearly illustrate this difference in the lateral heterogeneity (Table 1). Tomographic analysis of data obtained from these observations also shows considerable change in lateral velocity across the SKL (Kato et al., 2005a). Although most aftershocks in the JMA catalogue had focal depths deeper than $10 \mathrm{~km}$, the relocated hypocenters determined by the temporary array deployed in this study range in depth from 3 to $17 \mathrm{~km}$. This difference could be attributed to the fact that the routine determinations listed in the JMA catalogue do not consider the lateral variation in seismic velocity.

Several clusters that formed dipping distributions were apparent in aftershock distribution (Fig. 4). The main shock was located at the deepest end of the west-dipping highangle $\left(60^{\circ}\right)$ distribution. Those aftershocks were distributed at a range in depth of between 3 to $11 \mathrm{~km}$ and a width of approximately $20 \mathrm{~km}$, which represents the source fault plane of the main shock. The shallower extension of this distribution appears at the surface between the Yukyuzan Fault and the SKL. The largest aftershock (M6.5) occurred on October 23 at 18:35 and was located on the deepest end of the other west-dipping distribution, located approximately $5 \mathrm{~km}$ east and separate from the distribution of the main shock. Those aftershocks were distributed at depths ranging between approximately 8 to $16 \mathrm{~km}$ and a width of approximately $10 \mathrm{~km}$, which represents the fault plane of the largest aftershock. The shallower extension of this distribution was located aboveground on the SKL.

The October 27, 10:40 aftershock (M6.1) was located on the deepest end of the southeast dipping low-angle distribution and it was perpendicular to that of the largest aftershock. This distribution has a depth of approximately 9 to $14 \mathrm{~km}$ and a width of about $10 \mathrm{~km}$ which represents the fault plane of the aftershock. It is thus clear that the main shock and largest aftershocks occurred on at least three different source faults, potentially related to the surface geology with fault orientations that are mutually conjugate.

Since many more earthquakes may have occurred than were listed in the JMA catalogue, we examined the continuous record visually. We detected 4071 events and selected 3102 hypocenters with spatial errors of less than $0.5 \mathrm{~km}$ in the horizontal direction and less than $1.0 \mathrm{~km}$ deep. Particular care was taken when examining the 10-hour period preceding the M6.1 aftershock on October 27 in the eastern area. We detected 981 events for this period (smallest magnitude of 0.0 ) but no earthquake occurred in 10 hours before the M6.1 aftershock (Fig. 5). This observation indicates that the aftershock area expanded to eastward after the M6.1 aftershock on October 27 and also that no foreshocks of significant amplitude occurred, at least at levels that could be used to determine their location.

The JMA routine catalogue also indicated that the westdipping high-angle distribution near the largest aftershock, located $5 \mathrm{~km}$ from the main shock source fault, appeared only after the largest aftershock had occurred. These observations suggest that, in the source area of the mid-Niigata prefecture earthquake, successive generations of large-tomoderate size source faults were responsible for the large number of aftershocks experienced during the study period. The separate source faults may be attributed to the strong heterogeneity of the source area (Hirata et al., 2005).

\section{Conclusion}

One day after the main shock we deployed a temporary seismic array in the source area of the 2004 Mid-Niigata Prefecture Earthquake. The five days observations of the aftershocks using the temporary seismic array enabled us to identify the three major source faults responsible for the main shock and the two major aftershocks. Two of the faults, the source faults responsible for the main shock and the largest aftershock, are parallel, steep west-dipping faults located approximately $5 \mathrm{~km}$ apart. The other fault 
dips eastward and is oriented perpendicularly to the westdipping faults. After considering the lateral heterogeneity of the crust, the epicenters determined in this study were located approximately $4.3 \mathrm{~km}$ west-north-west of those reported by the JMA routine catalogue. The strong heterogeneity of the crust is considered to be related to the geological and tectonic evolution of the area, a setting that provides numerous potential sites for moderate to large earthquakes. The prominent aftershock activity following the 2004 Mid-Niigata Prefecture Earthquake could therefore be attributed to the highly heterogeneous crustal structure of the area, coupled with E-W compression along the NiigataKobe line.

Acknowledgments. We would like to thank Hiroko Hagiwara, Takashi Iidaka and Toshihiko Igarashi for valuable discussion. We also thank Yoshiko Yamanaka, Tomonori Kawamura, Izumi Ogino, Masaru Kobayashi, Mamoru Saka, Masato Serizawa, Toshio Haneda, Yasuhiro Hirata and Shigeru Watanabe for the preparation, deployment and recovery of field equipment in this important study. We express our gratitude to Naoto Takeda, Erika Koguchi, Hitomi Kitagawa and Namiko Majima for their picking the arrival times. Most of the figures were created using GMT (Wessel and Smith, 1995). This work was supported by the Grantin-Aid for Special Purposes (16800054) and the Special Coordination Funds for the Promotion of Science and Technology offered by the Ministry of Education, Culture, Sports, Science and Technology of Japan (MEXT) under the title of, "Urgent Research for the 2004 Mid-Niigata Prefecture Earthquake", and a grant offered under the Earthquake Prediction Research program of MEXT.

\section{References}

Douglas, A., Joint epicenter determination, Nature, 215, 47-48, 1967. Headquarters for Earthquake Research Promotion, The promotion of Earthquake Research-Basic comprehensive policy for the promotion of earthquake observation, measurement, surveys and research, 1999 (in Japanese with English translation).
Hirata, N. and M. Matsu'ura, Maximum-likelihood estimation of hypocenter with origin time eliminated using nonlinear inversion technique, Phys. Earth Planet. Inter., 47, 50-61, 1987.

Hirata, N., S. Ohmi, S. Sakai, K. Katsumata, S. Matsumoto, T. Takanami, A. Yamamoto, T. Nishimura, T. Iidaka, T. Urabe, M. Sekine, T. Ooida, F. Yamazaki, H. Katao, Y. Umeda, M. Nakamura, N. Seto, T. Matsushima, H. Shimizu, and Japanese University Group of the Urgent Joint Observation for the 1995 Hyogo-ken Nanbu Earthquake, Urgent Joint Observation of Aftershocks of the 1995 Hyogo-ken Nanbu Earthquake, $J$. Phys. Earth, 44, 317-328, 1996.

Hirata, N., H. Sato, S. Sakai, A. Kato, and E. Kurashimo, Fault system of the 2004 Mid Niigata prefecture earthquake and its aftershocks, Landslides, 2(2), doi:10.1007/s10346-005-0050-8, 2005.

Kato, A., E. Kurashimo, N. Hirata, T. Iwasaki, and T. Kanazawa, Imaging the source region of the 2004 Mid-Niigata prefecture earthquake and the evolution of a seismogenic thrust-related fold, Geophys. Res. Lett., 32, L07307, doi:10.1029/2005GL022366, 2005.

Kato, A., S. Sakai, N. Hirata, E. Kurashimo, S. Nagai, T. Iidaka, T. Igarashi, Y. Yamanaka, S. Murotani, T. Kawamura, T. Iwasaki, and T. Kanazawa, Spatiotemporal variations of the aftershock distributions during one month after the occurrence of the 2004 mid-Niigata prefecture earthquake, Earth Planets Space, 2005 (submitted).

Natural Gas Mining Society and the Society of Exploration for Oil in the Continental Shelf, Oil and natural gas resources in Japan (Revised), 520 pp., 1992.

Obara, K., S. Hori, K. Kasahara, Y. Okada, and S. Aoi, Hi-net: High sensitivity seismograph network in Japan, Eos Trans. AGU, 81(48), Fall Meet. Suppl., Abstract S71A-04, 2000.

Takeda, T., H. Sato, T. Iwasaki, N. Matsuta, S. Sakai, T. Iidaka, and A. Kato, Crustal structure in the northern Fossa Magna region, central Japan, from refraction/wide-angle reflection data, Earth Planets Space, 56, 1293-1299, 2004.

Urabe, T. and S. Tsukada, A workstation-assisted processing system for waveform data from microearthquake networks, Abstracts of Spring Meeting of Seismological Society of Japan, 70, 1991 (in Japanese).

Wessel, P. and W. H. F. Smith, New version of the generic mapping tools released, Eos Trans. AGU, 76, 329, 1995.

S. Sakai (e-mail: coco@eri.u-tokyo.ac.jp), N. Hirata, A. Kato, E. Kurashimo, T. Iwasaki, and T. Kanazawa 